C. E. DENT AND M. FRIEDMAN: HYPOPHOSPHATAEMIC OSTEOMALACIA

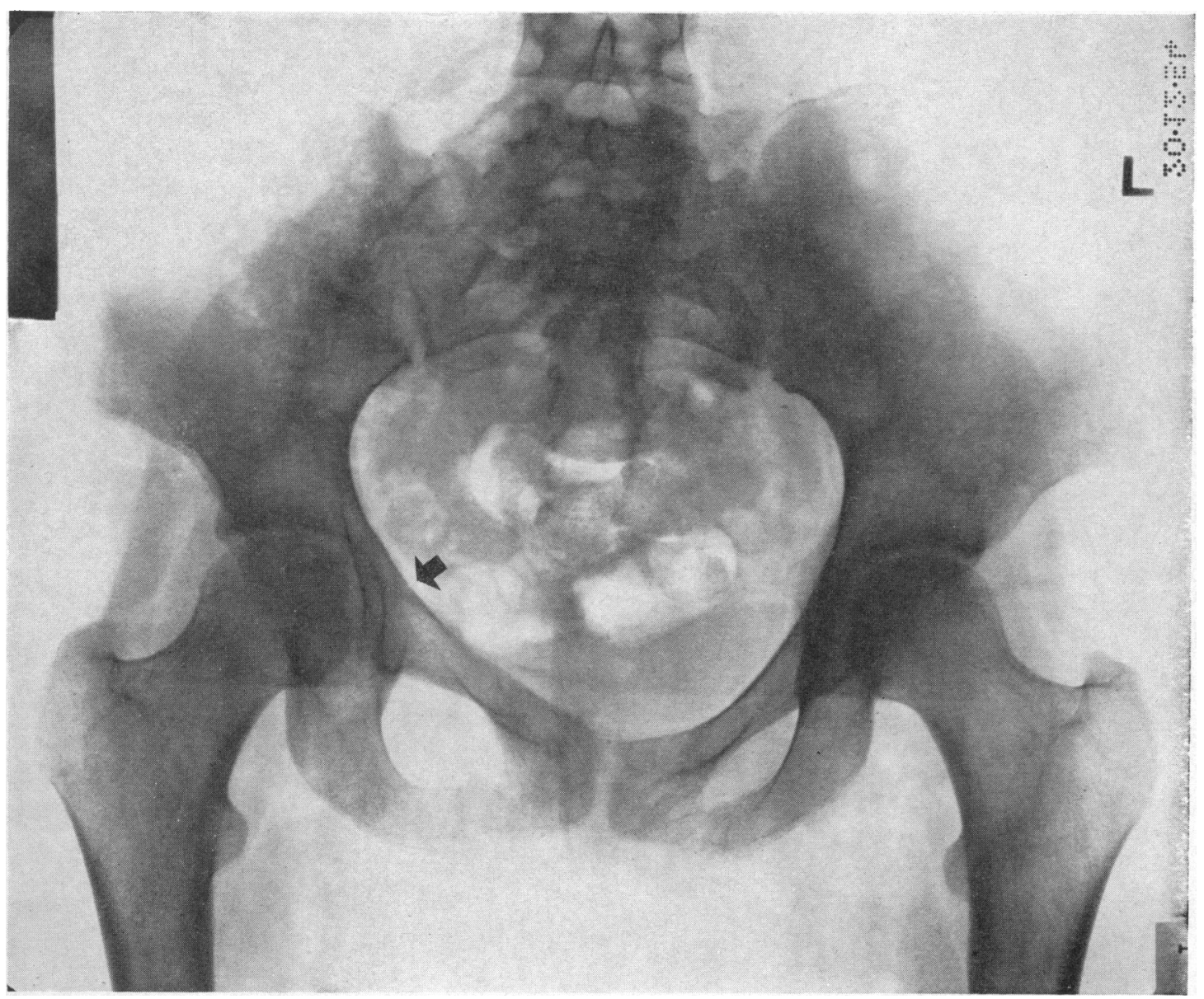

FIG. 2.-Radiograph of pelvis on 28 December 1963. The bones are quite normal in structure, but the pelvic asymmetry remains, as the only sign of her previous osteomalacia.

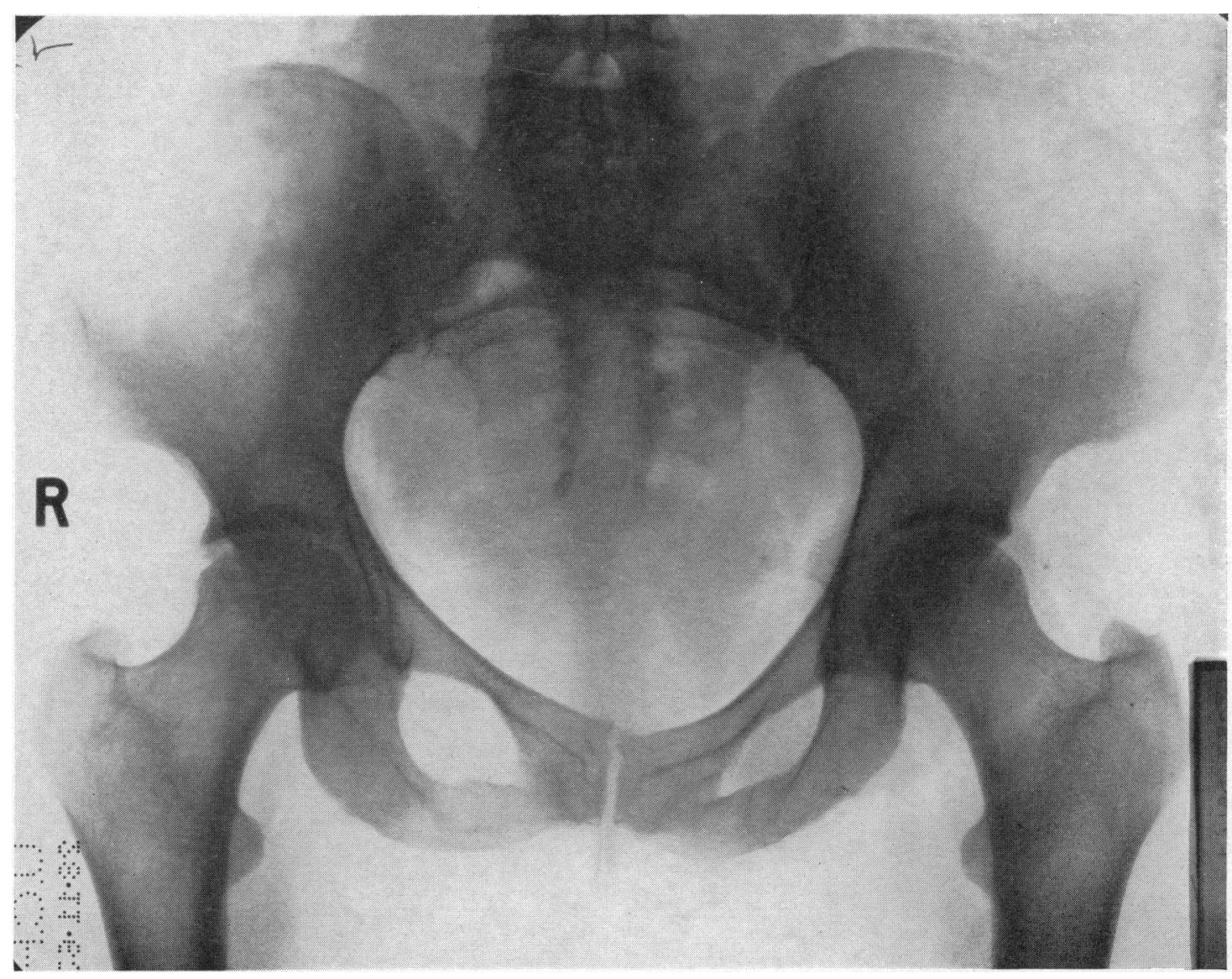

Fig. 1.-Radiograph of pelvis on 20 December 1954. This shows Looser's zones in both ischiopubic rami. There is also a tiny nick in the inner border of the pelvis opposite the right femoral head in the position of the maximum asymmetry (indicated by arrow). This

is an early Looser zone. 


\title{
Hypophosphataemic Osteomalacia with Complete Recovery
}

\author{
C. E. DENT,* M.D., F.R.S. ; M. FRIEDMAN,* M.B., B.CH., M.R.C.P.ED.
}

[With Special. Plate]

The original description of resistant rickets associated with hypophosphataemia was derived from detailed studies on a 16-year-old boy with a 14-year history of rickets (Albright, Butler, and Bloomberg, 1937). The bone disease in this patient failed to respond to a dose of vitamin $\mathrm{D}$ adequate to cure classical dietary rickets. Healing of the rickets was eventually obtained by the administration of enormous doses, 450,000 I.U. (11.25 mg.), of vitamin $\mathrm{D}$ daily. This study gave rise to the concept of "vitamin D resistance" occurring in certain types of rickets.

In the course of the past 25 years numerous studies have been made on this type of patient, and it is clear that a group of related diseases are involved. It has been shown that hypophosphataemia associated with normocalcaemia and a raised alkaline phosphatase was characteristic of the plasma biochemistry, no other biochemical abnormalities being present. Of particular importance has been the demonstration of a lowered renal phosphate threshold in this disease, which has led to suggestions that the disease may be primarily one of a specific renal tubular dysfunction (Robertson, Harris, and McCune, 1942), although the possibility of its being due to a form of secondary hyperparathyroidism is by no means yet excluded. Additional evidence for the tubular concept has been forthcoming with the recognition that hypophosphataemic rickets could be associated with various other tubular defects, some of these abnormalities being genetically determined. These facts led to an attempt to classify this group of diseases on the basis of the disorder of renal tubular function present (Dent, 1952; Fanconi and Girardet, 1952 ; Jackson and Linder, 1953 ; Fraser and Slater, 1958). The importance of distinguishing the various types lies in the fact that they may have a different treatment and prognosis. It was also to be expected that further permutations and combinations of tubular defects would be met in clinical practice. We have, for instance, recently studied two patients with rickets and a renal tubular defect for the reabsorption of calcium, phosphate, amino-acids, and protein (Dent and Friedman, 1964), a combination of renal tubular abnormalities not included in any of the original classifications.

The commonest form of hypophosphataemic rickets manifests itself usually between 6 months and 2 years of age. Male children are more severely affected than females and an autosomal sex-linked gene can be implicated to explain the strong hereditary pattern of the disease (Winters, Graham, Williams, McFalls, and Burnett, 1958). However, approximately onethird of cases present without a family history of the disease and are believed to be due to a gene mutation (Dent and Harris, 1956 ; Burnett, Dent, Harper, and Warland, 1964). Patients diagnosed in adolescence and adulthood can usually give a history of some features of the disease going back to childhood. For instance, they are likely to show dwarfism with typical rachitic deformities and marked relative shortening of the long bones. Renal function is normal except that a high clearance for phosphate can be demonstrated.

In contrast to the above commonest form of resistant rickets, some authors have described a further variant distinguishable by

* Medical Unit, University College Hospital, London. the absence of affected relatives, by the fact that the onset of the disease was in adolescence or early adult life, and in some cases also on account of the renal tubular dysfunction, including defective glycine as well as phosphate reabsorption (Dent and Harris, 1956 ; Segar, Iber, and Kyle, 1956 ; Frame and Smith, 1958 ; Henneman, Dempsey, Carroll, and Henneman, 1962). A preliminary report of one of our cases was published by Rose (1956). Subsequent follow-up has, however, demonstrated a unique feature in this particular patient. Not only did her recovery on treatment proceed better than is usual in such cases, but also she has remained in complete remission during the subsequent five years, during which treatment has been withheld. We are therefore now reporting her case more fully.

\section{Case Report}

The patient, born in 1935 of healthy unrelated parents, was perfectly healthy and active until the age of 16 years, when she began to experience dull aching pain in the region of both hips. Over the next two years the pains became progressively more severe. In addition a mild weakness of the pelvic-girdle muscles developed, resulting in a waddling gait and difficulty in climbing stairs. She also noticed aching in the region of her lower ribs, which was aggravated by movement, especially noticeable in bed at night. At the age of 18 she sought advice at her local hospital, where she was found to have osteomalacia with typical Looser's zones in several ribs and the pelvis. She was treated with calciferol $0.25 \mathrm{mg}$. $(10,000$ I.U.) daily, with some improvement in her symptoms. However, when the treatment was stopped her symptoms recurred.

In 1954 , at the age of 19 , she was referred to University College Hospital and admitted (17 December 1954) to the metabolic ward for further investigation. At this time she was severely incapacitated by pains in her hips and back, was very unsteady on her feet, and had a marked waddling gait. Her appetite was poor, and during the course of the year before admission her weight had fallen from 61.5 to $53.5 \mathrm{~kg}$. She had no food fads and her dietary intake was adequate in all respects. There was no abnormality of her bowels. She had no urinary symptoms. She had four elder sibs; all were healthy and there was no family history of bone disease.

Physical examination revealed a well-developed girl with a marked waddling gait. She had weakness of the pelvic-girdle muscles. There was no evidence of muscle-wasting. Her height was $63 \frac{1}{2}$ in. $\left(161 \mathrm{~cm}\right.$.), crown to pubis $29 \frac{1}{4}$ in. $\left(74.4 \mathrm{~cm}\right.$.), pubis to heel $32 \frac{1}{2}$ in. $(82.5 \mathrm{~cm}$.$) , and span 65 \frac{1}{2}$ in. $(166 \mathrm{~cm}$.). These measurements suggested a loss in height of the upper segment. There were no stigmata of old rickets, and no apparent bone deformity. There was marked bone tenderness. The rest of the examination showed nothing abnormal.

Investigations.-Plasma calcium $10.4 \mathrm{mg} . / 100 \mathrm{ml}$., phosphorus $2.1 \mathrm{mg} . / 100 \mathrm{ml}$., alkaline phosphatase $22.5 \mathrm{King}$-Armstrong units ; sodium $140 \mathrm{mEq} / 1$., potassium $5.4 \mathrm{mEq} / 1$., chloride $102 \mathrm{mEq} / 1$., bicarbonate $22.8 \mathrm{mEq} / \mathrm{l}$. Urea $33 \mathrm{mg} . / 100 \mathrm{ml}$. Urea clearance $91 \%$. Microscopical examination of urine normal, no reducing substances present. Maximum urinary concentration 1024 and dilution 1002 following water load. A phosphate infusion was carried out by Dr. J. M. Anderson, using the method later described (Anderson, 1955). It gave a glomerular filtration rate of $90 \mathrm{ml}$./ min., a mean inorganic phosphorus threshold of $1.7 \mathrm{mg} . / 100 \mathrm{ml}$. (normal 4-4.5), and a phosphate Tm of $1.5 \mathrm{mg} . / \mathrm{min}$. (normal 4-5). A 24-hour urine contained a urinary ammonia of $30 \mathrm{mEq}$ and titratable acidity of $20.3 \mathrm{mEq}$, random early morning urine $p \mathrm{H} 5.16$. 
An eight-day fat balance demonstrated an average fat excretion of 2.1 g. a day, representing $97 \%$ absorption of administered fat. The amino-acid chromatogram of the urine revealed a "super-glycine pattern "- that is, a large excretion of glycine in the absence of increased excretions of the other amino-acids. $X$-ray examination revealed numerous Looser's zones of the ribs and pubic rami (Special Plate, Fig. 1). There were no signs that rickets had been present in childhood. The renal outlines were normal in size. A barium meal and follow-through showed a normal small-gut pattern.

Calcium Balance Studies.-Calcium balances were performed as previously described (Dent, Harper, and Philpot, 1961). During the initial two six-day control periods the patient showed a low urinary $(50 \mathrm{mg} . / 24 \mathrm{hr}$.) and a high faecal calcium with a positive balance of $106 \mathrm{mg}$. of calcium a day (Fig. I). When vitamin D in the form of A.T. 10 (Bayer) was administered, after an initial delay there was an alteration in the partition between the faecal and the urinary calcium, the faecal calcium falling and urinary calcium rising to over $200 \mathrm{mg}$. a day. At the same time she went into markedly positive calcium balance and retained $600 \mathrm{mg}$. of calcium a day. These features before and after vitamin $\mathrm{D}$ are also typical of those seen in the commoner form of sex-linked hypophosphataemic rickets (Dent and Harris, 1956).

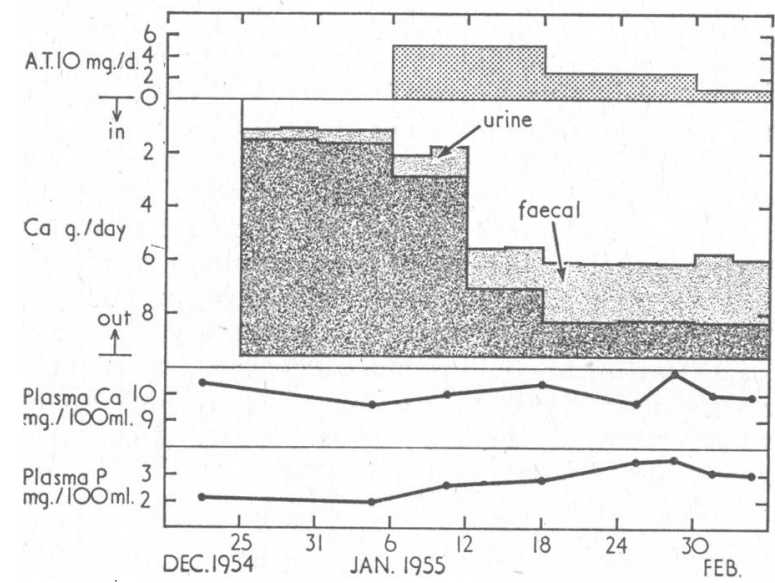

FIG. I.-Metabolic balance data. The results of giving A.T. 10 are shown. The balance data are plotted in the conventional fashion (Reifenstein, Albright, and Wells, 1945). The intake of calcium is measured downwards from the zero line. The output of faecal and urinary calcium is measured upwards. The clear space below the zero line represents the posituve balance or retention of calcium. Before treatment she has a high faecal and a low urine calcium. On giving large doses of A.T. 10, there is a large fall in the faecal calcium and a moderate rise in urine calcium, and she goes into strong positive calcium balance. This is maintained even when the dose of A.T. 10 is reduced. The plasma calcium has remained normal throughout the balance study. However, there was a significant rise in plasma phosphorus to near normal levels. The A.T. 10 was alleged to contain $1.25 \mathrm{mg}$. of dihydrotachysterol per $\mathrm{ml}$. of oily solution.

\section{Treatment and Progress}

After a short initial course of $4 \mathrm{ml}$. a day of oral A.T. 10 (alleged to contain the equivalent of $1.25 \mathrm{mg}$. of dihydrotachysterol per $\mathrm{ml}$.) she was put on a maintenance dose of $1 \mathrm{ml}$. daily. During the first two weeks of therapy she complained of increasing pain and stiffness of her limbs. This was followed by a marked improvement, with complete disappearance of her pain and stiffness. Her plasma phosphorus rose to $3 \mathrm{mg} . / 100 \mathrm{ml}$., and a repeat phosphate infusion showed a glomerular filtration rate of $93 \mathrm{ml} . / \mathrm{min}$., a rise in the phosphate threshold to $3.8 \mathrm{mg} . / 100 \mathrm{ml}$. and her phosphate $\mathrm{Tm}$ to $3.5 \mathrm{mg}$./min., both of the latter being low normal results (Anderson, 1955). The amino-acid chromatogram showed a less abnormal excretion of glycine. Calcification of Looser's zones began to appear in one month, and within three months the $x$-ray picture was completely normal. She was discharged from hospital on 8 February 1955 and insisted on getting married on 19 March 1955. Over the course of the next year her alkaline phosphatase fell to 10 K.A. units.

In June 1956 the A.T. 10 was discontinued, being replaced by capsules made up in our pharmacy containing $1 \mathrm{mg}$. of pure crystalline dihydrotachysterol (D.H.T.). This was done because round about this time we were beginning to have doubts about the potency of the commercially prepared A.T. 10. Our own capsules were regularly assayed for potency and were shown to be stable.

The D.H.T. therapy was continued for three and a half years, until September 1958, when it was discontinued because the continued clinical, biochemical, and radiological cure of her osteomalacia seemed better than we usually obtain with this form of treatment. Since that time there has been no recurrence of her symptoms. $X$-ray films have been normal (Special Plate, Fig. 2). Her serum phosphate has varied between 3 and $4 \mathrm{mg} . / 100 \mathrm{ml}$. The alkaline phosphatase has fallen steadily, and at the time of writing was 5 K.A. units. The amino-acid chromatogram showed a normal excretion pattern. The biochemical data during the entire period are shown in Fig. II.

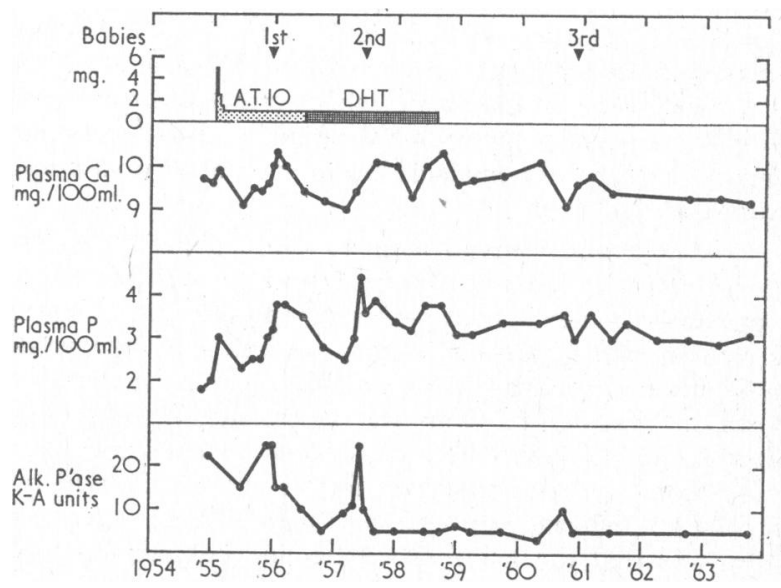

FIG. II.-Biochemical data over the nine-year follow-up period, showing the plasma calcium, phosphate, and alkaline phosphatase. Since discontinuing the D.H.T. in September 1958 there has been no rise in the alkaline phosphatase. Her plasma phosphorus still remains low normal in spite of clinical and radiological cure of her osteomalacia. Associated with each pregnancy there was a slight rise in her alkaline phosphatase and phosphorus levels.

During the follow-up period she has given birth to three children -in 1955, 1957, and 1960 - the first of these only a year after her original admission date to U.C.H. All pregnancies were uneventful and delivery was per vaginam without difficulty. During the first two pregnancies there was a slight but definite elevation of plasma calcium, phosphorus, and alkaline phosphatase before delivery. This did not occur so markedly with the third pregnancy, when she was off the D.H.T. It is of interest that her first child was hypercalcaemic at birth, with a plasma calcium of $11.7 \mathrm{mg} . / 100 \mathrm{ml}$., which fell to normal after the seventh day. This transient hypercalcaemia was not present in the subsequent two infants. (We have unpublished evidence from other patients that high vitamin D dosage during pregnancy greatly raises the plasma vitamin $D$ of the baby.) All the children are normal and show no evidence of rickets or hypophosphataemia.

At the time of writing the patient was extremely healthy. She had no disability whatsoever and was able to cope effectively with the management of the family and home.

\section{Discussion}

Osteomalacia, which is the adult counterpart of rickets, is a generalized disease of bone, and is characterized by a lack of calcification of newly formed normal bone matrix. The bones are therefore weaker and softer than normal and tend to form microfractures with the minor stresses and strains to which they are always subjected. The fractures thus occurring cannot heal normally owing to the defect in calcification at the fracture site. They tend to refracture at the same sites and become larger, so that eventually when viewed radiologically they show the typical picture of Looser's zones ("pseudofractures"). The biochemical changes occurring in osteomalacia are a low or normal plasma calcium and inorganic phosphorus, and an elevated alkaline phosphatase. Clinically, patients with the disease present with vaguely localized pains on movements or weightbearing and with proximal muscular weakness. Our patient 
presented with the clinical, biochemical, and radiological signs of osteomalacia.

The essential features of this case seem to be perfect health until the age of 16 years, followed by a progressive illness characterized by pain, extreme weakness, and the development of the other signs of osteomalacia, without any suggestion of any dietary, intestinal, or renal glomerular insufficiency as a cause for the osteomalacia. The diagnosis of osteomalacia was finally confirmed when she was shown to respond with complete clinical and radiological cure to large dose of vitamin $D$. The onset of the disease during puberty excludes the common type of sex-linked hypophosphataemic vitamin-D-resistant rickets which presents during the first few years of life (Dent and Harris, 1956 ; Burnett et al., 1964). Furthermore, in patients with the infantile-presenting type of vitamin-D-resistant rickets, the rickets becomes quiescent when growth ceases, although osteomalacia usually develops later in life. In contrast to this, in our patient the osteomalacia began soon after final epiphysial closure had occurred.

All the evidence seems to point to the fact that we are dealing with a disease which is different from the common hereditary hypophosphataemic vitamin-D-resistant rickets. She had, nevertheless, the same renal phosphate leak as in the sex-linked disease, and, as in this disease, she also showed a marked malabsorption of calcium from the gastro-intestinal tract before treatment with vitamin D. This block in calcium absorption was overcome by the administration of vitamin $\mathrm{D}$, which made the calcium balance strongly positive (Fig. I). An unusual feature was that the urine showed a large excretion of glycine on the paper chromatogram of the urinary amino-acids. This we believe may be due to an increased clearance of glycine, due to a defective reabsorption of glycine by the kidney tubules. We have not measured the renal amino-acid clearance in this case ; however, we have studied the amino-acid clearance in two other patients with the same presenting diseases as the present one but in whom no remission has later occurred. The results have been published by Cusworth and Dent (1960), under the headings of severe osteomalacia with increased glycine excretion, and they showed a decreased renal tubular reabsorption of glycine in both cases. The significance of the excess of glycine excretion is uncertain, but is further evidence of a selective interference with renal tubular function, which appears to be closely related to the underlying mechanism of this disease.

We cannot put forward a reasonable explanation why our patient should suddenly develop severe osteomalacia at the age of 16. A few of the other cases in the literature, however, started at this age. In none of these cases was there dietary deficiency, nor was there evidence to incriminate poisoning by a heavy metal or other toxin causing renal tubular damage. It seems possible that puberty in some way triggered off the disease process in a predisposed individual. There was nothing to suggest that the defect was hereditary.

The cases reported by Linder and Vadas (1931), Michaelis (1932), Leedham-Green and Golding (1937-8), and MonierVinard (1940) are very similar to our case in the mode of presentation. All presented with the clinical and radiological picture of osteomalacia just after puberty, but only the later case showed improvement when treated with vitamin D. Linder's case gave no response to vitamin $\mathrm{D}$, but the dose $(18,000$ I.U. a day) was rather low. In none of the above cases was amino-acid chromatography of the urine carried out, since the studies antedated the discovery of this technique.

McCance (1947) reported a case of a young girl who developed severe osteomalacia for the first time at the age of 14 years. She was cured by a single course of 500,000 I.U. of calciferol given daily for 42 days. We understand that she has since remained well without any further treatment than that described in the original publication (McCance, personal communication). So far as we are aware this is the only other patient who has remained symptom-free after the withdrawal of vitamin D. McCance introduced the term " raised resistance to vitamin D," or R.R.D., to describe the original findings in his patient.

Segar et al. (1956) reported the case of a male patient who presented with severe osteomalacia at the age of 20 . He was treated with 100,000 I.U. of vitamin D daily without any clinical or radiological response, in spite of hypercalcaemia resulting from the excessive vitamin D action. Two further cases have been reported, by Frame and Smith (1958) and by Henneman et al. (1962). Both of these cases had an excess of glycine excretion in the urine. We have studied in detail three other patients with late onset of osteomalacia, all of whom had a normal plasma calcium, a low plasma phosphorus, and an excessive excretion of glycine in the urine. These three and our own patient were briefly mentioned by Dent and Harris (1956); these other three we hope to report on fully in the near future, when it will be more appropriate to discuss the more general problems of pathogenesis of these particular forms of osteomalacia.

The remarkable feature of our case, and of that of McCance (1947), is that spontaneous recovery occurred, in his case after only one short course of treatment ; in ours this may also have been so, although we did not think of withholding treatment until four years after we had begun. The other similar cases in the literature, and our other three similar cases, have also been remarkable for their severity of manifestation, but in contrast have shown considerable intractability to the usual treatment with large doses of vitamin $\mathrm{D}$. We have to argue either that two entirely different disease processes are occurring in patients, at first clinically indistinguishable, or that the same disease might at first go through a temporary phase at which energetic treatment could produce a complete cure, not obtainable later in the disease. We are aware of no other instances of complete remission of the disease in the large group of "vitamin-D-resistant" types of osteomalacia. The situation presents us with a considerable challenge.

\section{Summary}

The case is described of a girl who presented at the age of 16 years with clinical and radiological signs of osteomalacia. Distinctive biochemical features were a marked hypophosphataemia, normocalcaemia, an elevated alkaline phosphatase, and hyperglycinuria. She was treated with large doses of vitamin $\mathrm{D}$, which brought complete clinical recovery. The vitamin $\mathrm{D}$ was administered over a four-year period, and since the vitamin $\mathrm{D}$ was discontinued she has remained well and has had no recurrence of signs and symptoms of osteomalacia over the subsequent five-year follow-up. Throughout this latter period her plasma phosphorus has remained low normal. A malabsorption syndrome and renal tubular acidosis were excluded by the appropriate tests.

We wish to thank the nurses, dietitians, and biochemists of the metabolic ward for their help during the in-patient admission and subsequent follow-up of this patient. We are most grateful to Dr. T. D. Kellock for referring the patient.

\section{REFERENCES}

Albright, F., Butler, A. M., and Bloomberg, E. (1937). Amer. f. Dis. Child., 54, 529 .

Anderson,'J. (1955). F. Physiol. (Lond.), 130, 268.

Burnett, C. H., Dent, C. E., Harper, C. M., and Warland, B. J. (1964). Amer. F. Med. In press.

Cusworth, D. C., and Dent, C. E. (1960). Biochem. F., 74, 550.

Dent, C. E. (1952). F. Bone ft Surg., 34B, 266. and Friedman, M. (1964). Arch. Dis. Childh., 39, 240. Harper, C. M., and Philpot, G. P. (1961). Quart. F. Med., 30, 1. - and Harris, H. (1956). F. Bone $f_{t}$ Surg, 38B, 204.

Fanconi, G., and Girardet, P. (1952). Helv. paediat. Acta, 7, 14.

Frame, B., and Smith, R. W. (1958). Amer. 7. Med., 25, 771.

Fraser, D., and Slater, R. B. (1958). Ped. Clin. N. Amer., p. 417. 
Henneman, P. H., Dempsey, E. F., Carroll, E. L., and Henneman, D. H. (1962). Metabolism, 11, 103.

Jackson, W. P. U., and Linder, G. C. (1953). Quart. F. Med., 22, 133.

Leedham-Green, J. C., and Golding, F. C. (1937-8). Brit. f. Surg., 25, 77.

Linder, G. C., and Vadas, D. G. M. (1931). Lancet, 2, 1124.

McCance, R. A. (1947). Quart. F. Med., 16, 33.

Michaelis, L. (1932). Fortschr. Röntgenstr., 45, 187.

Monier-Vinard, R. (1940). Bull. Soc. méd. Hôp. Paris, 56, 529.
Reifenstein, E. C., jun., Albright, F, and Wells, S. L. (1945) f. clin Endocr., 5, 367.

Robertson, B. R., Harris, R. C., and McCune, D. J. (1942). Amer. F. Dis. Child., 64, 948 .

Rose, G. A. (1956). Brit. med. f., 2, 805.

Segar, W. E., Iber, F. L., and Kyle, L. H. (1956). New Engl. Y. Med., 254, 1011.

Winters, R. W., Graham, J. B., Williams, T. F., McFalls, V. W., and Burnett, C. H. (1958). Medicine (Baltimore), 37, 97.

\title{
Prolonged Streptomycin and Isoniazid for Pulmonary Tuberculosis
}

\author{
R. N. JOHNSTON,* M.D., M.R.C.P., F.R.C.P.ED. ; D. H. SMITH,* M.D. \\ R. T. RITCHIE,* M.B., M.R.C.P.ED. ; W. LOCKHART,*† M.B.
}

Brit. med. F., 1964, 1, 1679-1683

Streptomycin and isoniazid are the most effective drugs in the treatment of tuberculosis. There are many reports on isoniazid dosage from 200 to $1,000 \mathrm{mg}$. daily but few on the optimal dose of streptomycin.

A daily dose of $1 \mathrm{~g}$. has become widely accepted, especially as toxicity is low in young patients receiving this drug for only three to six months. More recently, dissatisfaction with the self-administration of para-aminosalicylic acid (P.A.S.) and recourse to streptomycin and isoniazid for longer periods in elderly patients has shown that labyrinthine damage due to streptomycin is a troublesome and serious complication. The prolonged use of streptomycin and isoniazid made it desirable to explore methods for diminishing the incidence of labyrinthine damage without loss of therapeutic efficiency. Reduction of the dose of streptomycin to $0.75 \mathrm{~g}$. daily appeared to be a reasonable compromise, and preliminary results have already been reported (Johnston et al., 1961). Penman et al. (1957) found that pantothenic acid alleviated the vertigo of streptomycin. We were unable to trace any reports on the use of pantothenic acid to prevent labyrinthine damage due to streptomycin. We therefore decided to explore this possibility, to study $0.75 \mathrm{~g}$. of streptomycin and high-dosage isoniazid. With this background we planned the following controlled clinical trial in 1958.

\section{Method}

All new patients over the age of 15 years admitted to hospital with active pulmonary tuberculosis were accepted with the following exclusions : previous antituberculous chemotherapy, primary tuberculosis, diabetes mellitus, pneumoconiosis, nonEuropeans, and expectant mothers. From November 1958 to December 1959138 patients were accepted. When a patient was admitted to the trial the name was forwarded to a central secretary, who chose a card at random from a series specifying one of the following three regimens:

(1) S.I.=Streptomycin sulphate 1 g. daily plus isoniazid $1,000 \mathrm{mg}$. given in two divided doses with pyridoxine $50 \mathrm{mg}$. b.d. (After leaving hospital, isoniazid reduced to $600 \mathrm{mg}$. once daily plus pyridoxine $100 \mathrm{mg}$. once daily.)

(2) S.P. = Streptomycin sulphate $1 \mathrm{~g}$. daily with pantothenic acid $150 \mathrm{mg}$. orally daily at the same time plus isoniazid $100 \mathrm{mg}$. b.d. (After leaving hospital $200 \mathrm{mg}$. of isoniazid daily as a single dose.)

(3) $S .3=$ Streptomycin sulphate $0.75 \mathrm{~g}$. as a single injection plus isoniazid $100 \mathrm{mg}$. b.d. (After leaving hospital 200 mg. of isoniazid daily as a single dose.)

\footnotetext{
- Department of Tuberculosis, University of St. Andrews, and Chest Service, Dundee.
}

† Dr. Lockhart died on 27 May 1964.
In addition, each patient received P.A.S. 12 g. daily for the first six weeks. After leaving hospital streptomycin and isoniazid were given daily except Sundays to complete 18 month'' chemotherapy. By 1960 we were satisfied that the S.l regime merited further examination. During that year and 1961 we admitted a further 37 patients who fulfilled the same criteria except that they had to be sputum-positive initially. This latter group was not allocated by random selection, and is considered separately and styled the late S. $\frac{3}{4}$ group.

Initial examination in hospital included a radiograph of chest, tomography, and a minimum of three sputum specimens or laryngeal swabs. The former were stained for acid-fast bacilli and cultured on Loewenstein-Jensen media for Mycobacterium tuberculosis. Sensitivity tests were performed to streptomycin, P.A.S., and isoniazid on all positive cultures, using solid media, and all tests were performed against the standard H.37 Rv. strain. In the case of streptomycin and P.A.S. the organism was regarded as resistant if the test strain was four or more times resistant to the drug, compared with the H.37 Rv. culture. Resistance to isoniazid was shown by a growth of more than 20 colonies on the tube containing 0.2 $\mu \mathrm{g}$ of isoniazid per $\mathrm{ml}$. In addition to routine ward tests the urine was examined in the central laboratory for protein together with microscopy of the deposit. Renal function was further assessed by the blood urea and measurements of the streptomycin serum levels at 1 hour and 24 hours after the streptomycin injection. These latter bio-assays were performed after the P.A.S. had been discontinued and using the same strain of Klebsiella pneumoniae known to be streptomycinsensitive. The E.S.R. was measured by the Westergren method. Subsequently two sputum smears and cultures were examined every two weeks until discharge, with radiographs of chest and E.S.R. monthly.

At three-monthly intervals from the start of treatment, in addition to the above, clinical examination included the Romberg test, examination for nystagmus, and observations of the patient's gait. Later we reinforced the Romberg test by asking the patient to "about turn" with closed eyes and heels together. When a patient complained of dizziness or a tendency to stagger, these tests were repeated, and included the Hallpike caloric test (Hallpike, 1956). We assessed the degree of vertigo as follows : "doubtful," where the symptoms were very mild, unsupported by clinical examination and caloric tests, and where the patient's behaviour raised doubts ; "slight," transient or intermittent dizziness/ataxia with or without nystagmus ; "moderate," more persistent but less than "severe," obvious ataxia requiring support. Where we assessed the symptoms as doubtful we continued injections during a further few days. If symptoms continued even though they were then only mild and unsupported by objective evidence of labyrinthine damage 